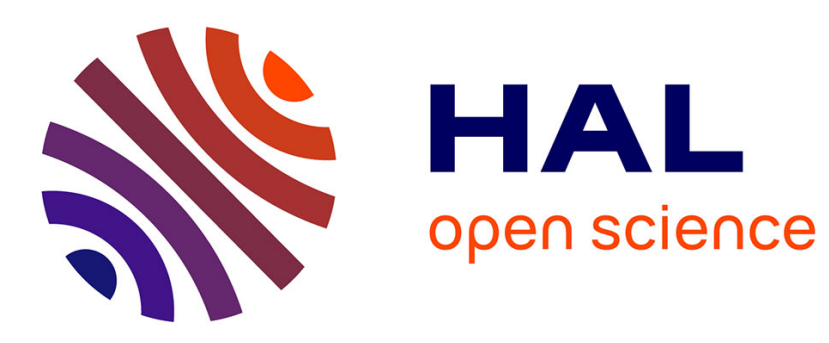

\title{
IPD Methodology in Shipbuilding
}

Hajnalka Vaagen, Lucky C. Masi

\section{To cite this version:}

Hajnalka Vaagen, Lucky C. Masi. IPD Methodology in Shipbuilding. IFIP International Conference on Advances in Production Management Systems (APMS), Sep 2019, Austin, TX, United States. pp.546-553, 10.1007/978-3-030-30000-5_67. hal-02419260

\section{HAL Id: hal-02419260 \\ https://hal.inria.fr/hal-02419260}

Submitted on 19 Dec 2019

HAL is a multi-disciplinary open access archive for the deposit and dissemination of scientific research documents, whether they are published or not. The documents may come from teaching and research institutions in France or abroad, or from public or private research centers.
L'archive ouverte pluridisciplinaire HAL, est destinée au dépôt et à la diffusion de documents scientifiques de niveau recherche, publiés ou non, émanant des établissements d'enseignement et de recherche français ou étrangers, des laboratoires publics ou privés. 


\title{
IPD Methodology in Shipbuilding
}

\author{
Vaagen, Hajnalka and Masi, Lucky C. \\ 1 Norwegian University of Science and Technology (NTNU), Department of Ocean \\ Operations and Civil Engineering, Faculty of Engineering Science \\ 2 Norwegian University of Science and Technology (NTNU), Department of Ocean \\ Operations and Civil Engineering, Faculty of Engineering Science
}

\begin{abstract}
This paper proposes an Integrated Project Delivery methodology in shipbuilding from the perspective of design function, to validate with limited design knowledge whether the project can satisfy unified project goals. This is achieved by aligning real-time information flow with the design development process. The methodology is built on a systematic, multidisciplinary theoretical analysis and triangulation of methods and principles from ship design, lean construction, the collaborative BIM software, and multi-stage thinking from decision theory.
\end{abstract}

Keywords: Integrated Project Delivery · ship design · design uncertainty $\cdot$ lean construction.

\section{Problem Description}

This paper considers engineer-to-order (ETO) shipbuilding, where the project delivery complexity is defined by frequent design changes throughout the project execution, and concurrent activities to reduce time to market [15]. This is leading to continuous disturbances and updates, altering activities to be performed and their sequencing, not only changing the duration of predefined activities [29]. Traditional project risk management approaches with disconnected functions, and buffering around statistically describable uncertainty under fixed design [20, 21], often fail in this context [2,29]. The implication of disconnected design and planning functions is that of design information fragmentation. This is leading to frequent changes in technical specifications, schedules that fail to consider the design uncertainty [14], and potentially complex and costly updates throughout the project delivery [29].

With many projects characterized by high and difficult to quantify levels of uncertainty, and model based planning that fails to adequately handle the complexity $[2,26,8]$, new approaches to project delivery, building on collaborative processes, are emerging. One is Integrated Project Delivery (IPD), a relational contracting approach that early aligns project objectives with the interest of key stakeholders through shared risk and reward [3]. The aim of IPD is to achieve team integration in order to improve procurement and the project delivery process [24], and to overcome problems caused by information fragmentation. 
IPD creates an organization able to apply the principles of lean project delivery [22], arguing for project phases being intertwined by a common cause, and not separable as commonly done in traditional approaches. Lean project delivery aims to effectively involve downstream stakeholders in front-end loading (or preproject planning), through cross functional teams, to e.g. pursue objectives that may change during the course of the project, and to integrate this knowledge into plans and strategies $[4,6]$. Construction Industry Institute defines front-end loading as the process of developing sufficient strategic information with which stakeholders can address risk and make decisions in order to maximize the potential for project success [12]. Front-end loading may add a certain amount of time and cost to the early project phases, but reduces the impact of disturbances.

While the number of professionals supporting the advancement of IPD is increasing [3], the number of projects using IPD is limited [7]. There are several reasons to this. Stakeholders hesitation to share key technical and market information is one reason. A second is that, to fully leverage on the benefits of integrated approaches, a collaboration and information sharing solution is needed, such as Building Information Modelling (BIM) [3]. BIM is a digital model of construction bringing design activities closer to the customer and production, serving as a collaboration platform across stakeholders and disciplines, allowing full information transparency [24], and assisting the management of construction projects [10]. The integration of lean principles with BIM functionalities (like 4D scheduling into the Last Planner System of planning and control to enhance workflow reliability [9]), enables cost effective exploration of alternative design and construction models in early project phases. When IPD and BIM are used in conjunction, the expectations for the project to be completed successfully are increased [18]. BIM requires software interoperability [16], which is a challenge in shipbuilding due to the many heterogeneous applications in use, along the dynamics and adaptability needed to operate in this sector [1]. A third reason is related to enabling a collaborative design and planning process to prove (or disprove), with limited design knowledge, whether the project can satisfy unified cost, time and risk requirements [19]. A such validation process requires allowing multiple values of design parameters, that are selected or down-selected at key decisions points. One example is the Toyota set-based development approach [28], which differs from point-based design where decisions are iterated and modified over a fixed design. See [27] for the difference between point-based and set-base design. While the value of such real options is recognized, it is less clear how to operationalize them in planning and project delivery. Lean construction has justified its implementation by significant improvements in time, cost and quality estimates, and its organizational integration approaches help identifying how to structure to project delivery to make it more flexible $[4,25]$. But its Last Planner System has not explicitly addressed options for flexibility [5], apart from advising that master control schedules are kept at the level of milestones between project phases, and planning in greater detail as time for execution approaches [4]. This may explain why projects in dynamically chang- 
ing environments struggle with lean and IPD customization to their uncertain context.

Given the quantified impact of design changes on project performance [29], and the third challenge for IPD implementation listed above, this paper addresses the following research question: How to achieve a collaborative design and planning process under limited design information to enable IPD in shipbuilding, and to enable late changes with least disturbance.

The research approach is briefly described in Section 2, the IPD methodology and exemplification of concepts in Section 3, and conclusion in Section 4.

\section{Research Approach}

The research is built on a systematic, theoretical analysis and triangulation of methods applied to the design and development of uncertain project, and an active engagement in the shipbuilding industry in Norway with interview based studies. The methodology offers the theoretical understanding for the choice of methods and best practices that can be applied to the shipbuilding case. While particular methods are industry specific, the developments apply to ETO projects at large. The research is multidisciplinary, building on principles from ship design, lean project management, multistage thinking from decision theory, and collaborative BIM principles.

\section{IPD Methodology - a Design Planning Perspective}

This section describes the IPD methodology to enable a collaborative design and planning process under limited design information. This is done by aligning the design model development and validation process to real-time information throughout the project delivery. The validation process builds on a unified project value -the owners business case within the stakeholders allowable time, cost and quality constraints, and within acceptable level of risk-, and requires a systems-oriented design workflow, where all aspects of the project lifecycle are embedded into design management. This calls for a shift in ship design, from that of the sole domain of naval architects and design engineers, to incorporate stakeholders into pre-planning, before the commencement of design.

For integration and validation under limited design, we triangulate lean concepts and the LPS terminology of [4] "should-can-will-did" with multi-stage thinking in decision theory, to address the following elements in front-end planning:

- Design information fragmentation and the minimal information needed to make design and planning decisions at important points in the project delivery. This refers to what information 'should' be enabled and when.

- Stakeholder capabilities to deliver requested minimal information. This is related to what 'can' we have as compared to 'should'. 
- A collaborative design planning and project delivery process that is aligned with 'should' and 'can', and enables design updates with least disturbance. This is connected to the design management and build strategy, i.e., the commitment of what 'will' be done.

\subsection{Design Information Fragmentation}

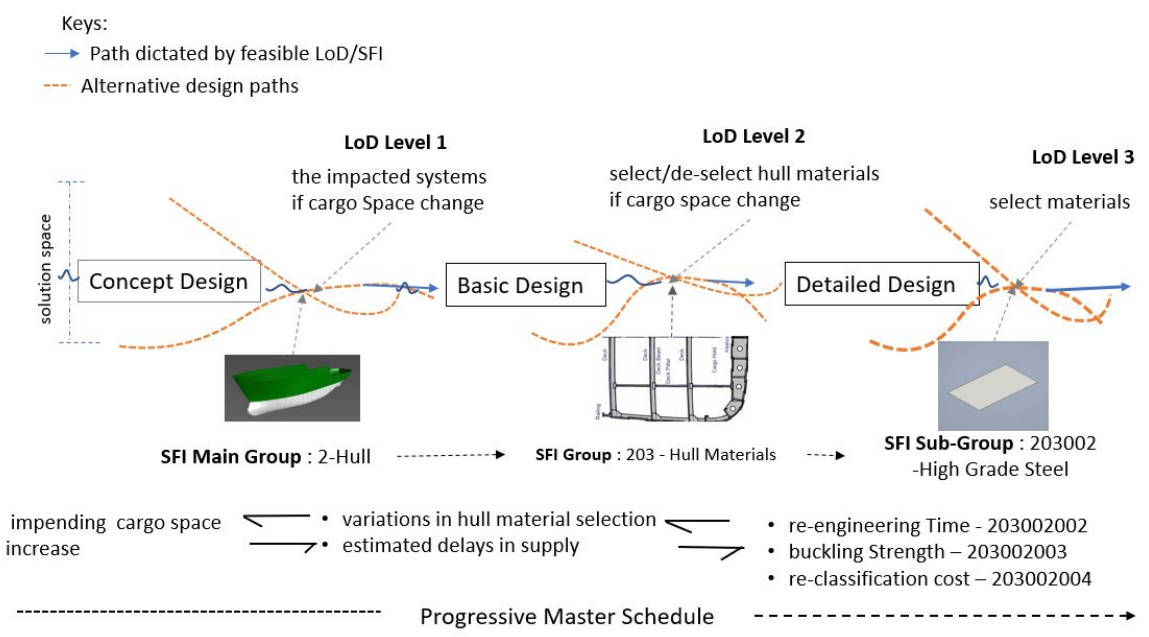

Fig. 1. LoD-SFI Embedded Project Timeline

Knowledge on the minimal information needed to make or update design decisions at important milestones is developed by applying the Level of Details (LoD) concept, adopted from the EUBIM Task Group [16] to the SFI coding and classification system for the maritime industry [23].

The LoD concept, building on design engineering and implementation constraints and advanced simulation of design variance, establishes a non-static design boundary, used for the assessment of design quality and maturity, information availability and accessibility of critical components at key phases. The SFI system provides a functional subdivision of technical and financial ship information, progressively detailed through subdivisions.

The combined LoD-SFI concept provides planners with necessary knowledge on what level of information (we call it minimal information) is needed for a $3 \mathrm{D}, 4 \mathrm{D}$ or $5 \mathrm{D}$ model of the vessel to satisfy unified project goals. The concept is exemplified by Figure 1 for a simple case of cargo space development on a cruise vessel, with hull structure, hull materials and high grade steel decisions. The dotted lines represent alternative design paths (i.e., the solution space) at concept-, basic- and detail design phases. The SFI technical and financial components where alternatives are allowed are concretized. 


\subsection{The Design Model Development and Validation Process}

To ensure the collaborative project validation process under limited design information, the project control workflow on Figure 2 is developed. This is illustrated for the concept phase, and to be replicated for subsequent phases.

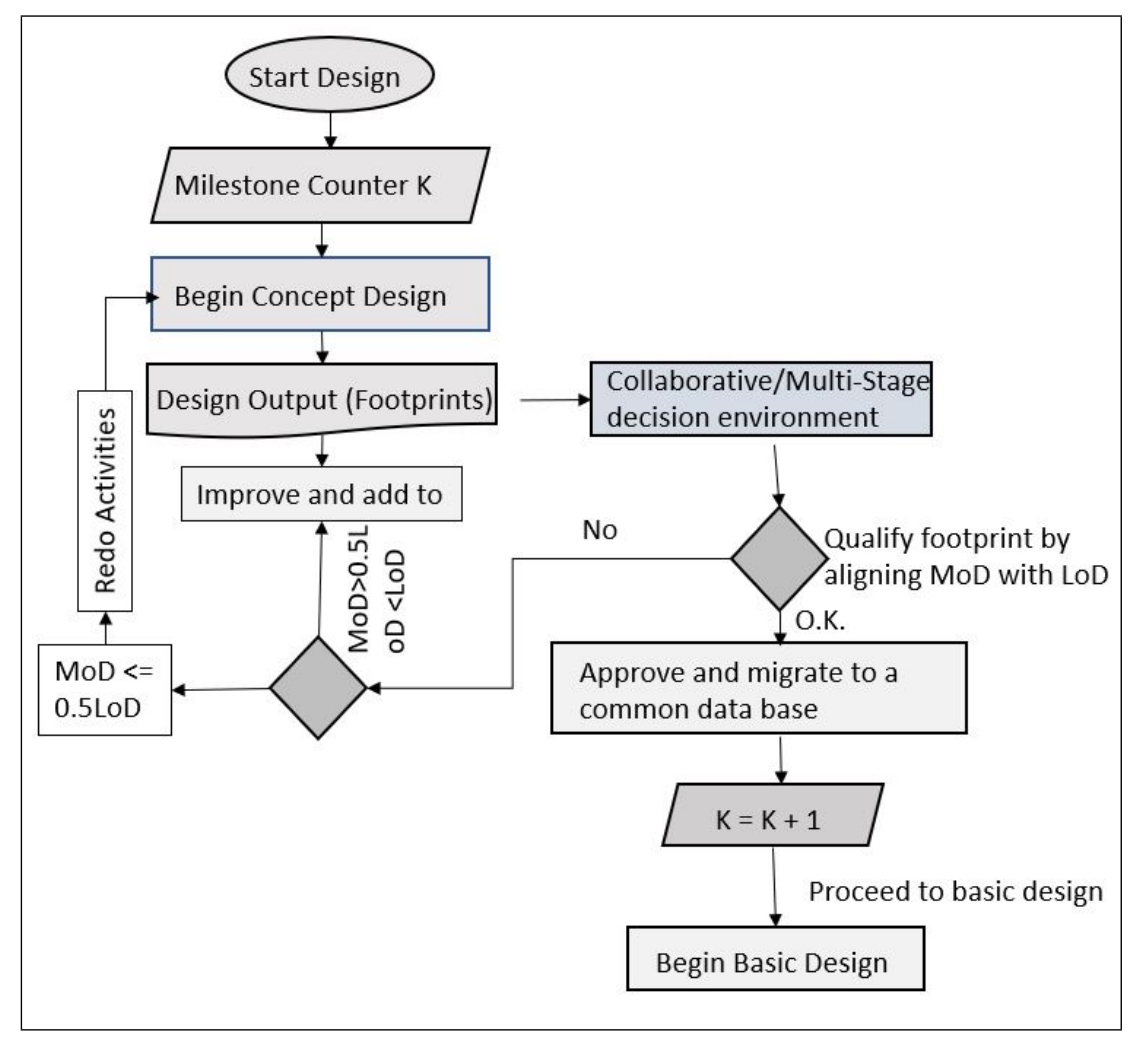

Fig. 2. IPD Collaborative Design Workflow

In this process, the design task begins and concept design commences. The combined LoD-SFI concept drives the minimal information to be requested for validation. The collaborative design workflow enables comparing and validating the design model maturity (call it MoD) against the pre-established LoD information (as illustrated on figure 1). For comparability of MoD to LoD we apply a 0 - 1 scale, where: Value 1 reflects full alignment of model maturity to what is expected; Values between 0 - 0.5 suggest a low level of alignment, where major revisions in project goals and/or alternative design solutions are needed; Values between 0.5 - 0.99 suggest partial alignment where multiple design alternatives are to be managed simultaneously. As the project progresses, the design management process is increasingly dif- 
ficult as more subsystems and their inter-dependencies must be addressed simultaneously.

The control flow dictates decision-making based on real time information, and facilitates collaboration for a multi-layer validation process. If the design model outputs, after evaluation, do not support the information flow from the client and main stakeholders, decision makers revert to initial condition (concept design here). This ensures that only value-generating work is accepted.

\subsection{Variation-Order Control}

To effectively manage design changes, a responsive plan is needed, i.e. a proactive approach where alternative designs can be selected/ down-selected based on real-time information. To identify points in time and activities where alternatives are needed, a front-end uncertainty assessment is required. With the difficulties to predict changes in advanced shipbuilding (often on the edge of known technology), a front-end assessment of change probabilities has limited value. An alternative approach is to assess the impact of potential changes on the system, disregard the probability of occurrence. This mitigates the need to deal with probabilities.

For the scope of this research, the impact and criticality of activities is assessed as follows. In first step, the Design Structural Matrix [11] is applied to the SFI system of coding for ships [23], to identify interdependencies and influences between SFI subsystems. In second step, lifecycle costing of these interdependent systems is performed. By exposing the criticality of activities from a system perspective, this approach serves as decision support to identify places in the design process where the limited uncertainty management resources are to be focused. For example, by keeping the design solution space open and allowing multiple parameter values. Advanced simulation, such as the virtual twin technology, allows to further explore these concepts, by varying parameter values and identifying alternative design alternatives and implementation paths. Because of space limitation, we omit the exemplification of this concept.

\section{Conclusion}

High design uncertainty in ETO projects triggers a move away from traditional point-based design, with selection of a final alternative as soon as possible, to strategies that consider multiple alternative designs in parallel and postpone the choice of a final alternative to as late as possible. The proposed collaborative methodology aims to enable project validation under limited design knowledge, by delaying design decisions and managing alternatives in parallel throughout the shipbuilding project delivery. The paper addresses neither the costs of design changes throughout the project, nor the

quantified benefit of options to effectively handle these. For that we refer to existing literature. 
The proposed IPD methodology incorporates concepts from lean project delivery, Building Information Modelling and multi-stage decision making (with stages defined by feasibility and information availability), into the ship design process.

While the developed concepts are demonstrated by small examples, future large-scale implementation is needed for further validation. This opens up for a discussion on both the software maturity within naval architecture, where traditional approaches are still dominating, and on the organizational and behavioural prerequisites to enable a collaborative design and project development culture.

The contribution of this paper is placed within a wider context of management of project uncertainty.

\section{References}

1. Adamus, L. W. (2013). BIM: Interoperability for sustainability analysis in construction. Central Europe Towards Sustainable Building: Integrated building design BIM, 1-4.

2. Atkinson, R., Crawford, L. and Ward, S. (2006). Fundamental uncertainties in projects and the scope of project management. International Journal of Project Management, [online] 24(8), pp.687-698. Available at: https://www.sciencedirect.com/science/article/abs/pii/S0263786306001438.

3. AIA California Council. (2014). Integrated Project Delivery: An Updated Working Definition.

4. Ballard, G., \& Tommelein, I. (2016). Current process benchmark for the last planner system. Lean Construction Journal, 89, pp 57-89.

5. Ballard, G. \& Vaagen, H.(2017). Project Flexibility in Lean Construction. In: Proceedings of the 25th Annual Conference of the International Group of Lean Construction Heraklion, Greece.

6. Ballard G. (2008).The Lean Project Delivery System: An Update. Lean Construction Journal

7. Becerik-Gerber, B., \& Kent, D. (2010). Implementation of integrated project delivery and building information modeling on a small commercial project. Journal of Construction Engineering and Management 136(8) 443-555

8. Böhle, F., Heidling, E., \& Schoper, Y., (2016). A new orientation to deal with uncertainty in projects. International Journal of Project Management 34(7), $1384-1392$

9. Bhatla, A.,\& Leite, F. (2012). Integration framework of BIM with the last planner system TM. In: IGLC 2012-20th Conference of the International Group for Lean Construction.

10. Bryde, D., Broquetas, M. and Volm, J. (2013). The project benefits of Building Information Modelling (BIM). International Journal of Project Management, 31(7), pp.971-980.

11. Browning, T. (2001). Applying the design structure matrix to system decomposition and integration problems: a review and new directions. IEEE Transactions on Engineering Management, 48(3), pp.292-306.

12. Construction Industry Institute (CII). (2002). CII best practices guide: Improving project performance. Implementation Resource 166-3. 
13. Eastman, C., Teicholz, P., Sacks, R., \& Liston, K. (2011). BIM handbook: A guide to building information modeling for owners, managers, designers, engineers and contractors. John Wiley \& Sons.

14. Eckert CM, Clarkson PJ.: The reality of design process planning. In: Proceedings of ICED 03, the 14th International Conference on Engineering Design, Stockholm 2003

15. Emblemsvaag, J. (2014). Lean Project Planning in Shipbuilding. Journal of Ship Production and Design, 30(2), pp.79-88.

16. EUBIM Task Group Homepage, http://www.eubim.eu/handbook/. Last accessed 9 March 2019.

17. Faniran, O., Love, P., Treloar, G. and Anumba, C. (2001). Methodological issues in designconstruction integration. Logistics Information Management, 14(5/6), pp.421-428.

18. Glick, S., \& Guggemos, A. (2009, April). IPD and BIM: benefits and opportunities for regulatory agencies. In Proceedings of the 45th ASC National Conference, Gainesville, Florida, April (Vol. 2, No. 4).

19. Grau, D., and Cruz Rios, F. (2019). Project Validation A guide to improving Owner value and team performance. School of Sustainable Engineering and the Built Environment, Ira A. Fulton School of Engineering, Arizona State University, Tempe, AZ, USA Version 1.0.

20. Herroelen W, Leus R. (2005). Project scheduling under uncertainty: Survey and research potentials. European journal of operational research 165(2) 289306 Sep 12005.

21. Herroelen W, Leus R, Demeulemeester E. (2002). Critical chain project scheduling: Do not oversimplify. Project Management Journal 33(4) pp. 48-60.

22. Matthews, Owen and Howell, Gregory A. (2005). Integrated project delivery an example of relational contracting. Journal of Lean construction 2(1) pp. 46-61.

23. Manchinu, A., \& McConnell, F. (1977). The SFI coding and classification system for ship information. In REAPS Technical Symposium.

24. Nofera, W and Korkmaz, S and Miller, VD and Toole, TM: Innovative features of integrated project delivery shaping project team communication. In: The 2011 Engineering Project Organizations Conference, Editor(s): T. Michael Toole, pp 1-17 Estes Park, Colorado (2011)

25. O. AlSehaimi, A., Tzortzopoulos Fazenda, P. and Koskela, L. (2014). Improving construction management practice with the Last Planner System: a case study. Engineering, Construction and Architectural Management, 21(1), pp.5164 .

26. Petit, Y. and Hobbs, B.(2010). Project Portfolios in Dynamic Environments: Sources of Uncertainty and Sensing Mechanisms. Project Management Journal, 41(4), pp.46-58 .

27. SINGER, D., DOERRY, N. and BUCKLEY, M. (2009). What Is Set-Based Design?. Naval Engineers Journal, 121(4), pp.31-43.

28. Sobek II, D. K., Ward, A. C.,\& Liker, J. K. (1999). Toyota's principles of set-based concurrent engineering. MIT Sloan Management Review, 40(2), 67

29. Vaagen, Hajnalka and Kaut, Michael and Wallace, Stein W,. (2017). The Impact of Design Uncertainty in Engineering-to-order Project Planning. European Journal of Operational Research 261(3) 1098-1109 